\title{
Diagnosis and management of parachute mitral valve and supravalvar mitral ring
}

\author{
Fergus J. Macartney, Olive Scott, Marian I. Ionescu, and Philip B. Deverall \\ From Killingbeck Hospital and The General Infirmary, Leeds
}

The results of investigation in 5 children with congenital deformities of the mitral valve region characteristic of the 'parachute mitral valve complex' were reviewed. Three patients had parachute mitral valve, $I$ had supravalvar mitral ring, and I had both these lesions. Associated anomalies included ventricular septal defect, double outlet right ventricle, subaortic stenosis, bicuspid aortic valve, and coarctation of the aorta.

Clinical presentation depended on which abnormality was dominant. However, all patients had clinical and haemodynamic evidence of mitral valve disease: stenosis in 4 patients and incompetence in I. In I patient the single, hypertrophied papillary muscle obstructed left ventricular ejection, mimicking hypertrophic obstructive cardiomyopathy.

Parachute mitral valve produced a specific angiocardiographic abnormality, a filling defect during diastole shaped like an egg-timer in the lateral left ventricular angiogram. This was produced by non-opacified blood posterior to the mitral leaflets and chordae tendineae converging towards the filling defect produced by the enlarged, single papillary muscle.

Supravalvar mitral ring produced a thin, crescentic, filling defect between the left atrium and ventricle, seen in the lateral view during opacification of the ventricle from the atrium.

Careful preoperative assessment of the relative importance of these multiple anomalies allowed successful surgical correction of the significant lesions in the 4 patients operated on. Of 3 patients with parachute mitral valve, 2 required mitral valve replacement. In $I$ of these a supravalvar ring was also excised. In the other patient with supravalvar mitral stenosis, excision of the ring alone relieved mitral obstruction adequately.

Congenital obstructive anomalies in relation to the left atrioventricular valve are a rare but important cause of disability in infancy and childhood. Supravalvar mitral ring has been reported by several groups (Rogers et al., 1955; Johnson and Dodd, 1957; Manubens, Krovetz, and Adams, 1960; Lynch et al., 1962; Shone et al., 1963; Cassano, 1964; Anabtawi and Ellison, 1965; Rao et al., 1969). Shone et al. (1963) described a complex of 'parachute mitral valve, supravalvar ring of the left atrium, subaortic stenosis and coarctation of the aorta,' in 8 cases. Most of these reports have described necropsy material, this, at least in part, resulting from the difficulties of establishing a diagnosis in life. The frequent association of other significant cardiovascular anomalies further complicates diagnosis.

This report is prompted by investigative and surgical experience with 5 children, 4 of whom

Received 30 November 1973. underwent operation and survived open intracardiac correction of multiple anomalies. These anomalies included supravalvar mitral stenosis, parachute mitral valve, subaortic stenosis, and ventricular septal defect. Two of the cases in addition had a pseudocoarctation of the aorta. One child had double outlet right ventricle with d-malposition of the great arteries. Apart from the surgical considerations, we believe this experience has suggested the means of diagnosing and assessing these anomalies before operation.

\section{Subjects and methods}

Five children, aged I month to I 3 years, are described. Cardiac catheterization was carried out by standard techniques. Intravascular pressures were measured from a point $10 \mathrm{~cm}$ above the catheterization table top. Calculations of pulmonary and systemic flows and resistance by the Fick method were based upon pressures and saturations from the great arteries and great veins measured either simultaneously or within five minutes 
of one another in a steady state except in Case 5, where conditions were unstable. Left atrial pressure was measured directly in 2 patients and indirectly in the remainder. The pulmonary capillary wedge pressure was validated in each case by withdrawal of blood with an oxygen saturation $>95$ per cent. Pulmonary venous saturation was assumed to be equal to systemic arterial saturation except in the presence of an intracardiac right-to-left shunt (Case 2) where 95 per cent saturated blood was withdrawn from the left ventricle just distal to the mitral valve, and assumed to represent pulmonary venous blood. Oxygen uptake was directly measured in 3 patients (Kappagoda and Linden, 1972), and assumed in
2 (LaFarge and Miettinen, 1970). Because one patient had functional subaortic stenosis, records of the remainder were analysed for post-extrasystolic diminution of pulse pressure (Braunwald et al., r964).

Rapid biplane Elema angiocardiograms were recorded with injection into various chambers, but in each case a left ventricular injection was performed with $\mathrm{r} \cdot 4-\mathrm{I} \cdot 8 \mathrm{ml}$ Conray 420 per $\mathrm{kg}$ body weight.

\section{Clinical, surgical, and pathological data}

The electrocardiographic, radiographic, and haemodynamic findings are summarized in Tables $I$ to 3 .

TABLE I Electrocardiographic findings

\begin{tabular}{|c|c|c|c|c|c|c|c|c|}
\hline $\begin{array}{l}\text { Case } \\
\text { No. }\end{array}$ & Rhythm & $R A H$ & $L A H$ & $R V H$ & $L V H$ & $\begin{array}{l}\text { Frontal } \\
\text { QRS axis }\end{array}$ & Frontal loop & Notes \\
\hline $\mathbf{I}$ & Sinus & + & - & + & - & $+120^{\circ}$ & Clockwise & \\
\hline 2 & Sinus & + & - & + & - & $+165^{\circ}$ & Clockwise & \\
\hline 3 & Sinus & + & + & - & + & $+45^{\circ}$ & Counterclockwise & $\begin{array}{l}T \text { wave inversion } \\
\mathrm{V}_{5}, 6\end{array}$ \\
\hline 4 & $\begin{array}{l}\text { Episodes of sinus } \\
\text { arrest with nodal } \\
\text { escape }\end{array}$ & - & - & - & + & 0 & Counterclockwise & $\begin{array}{l}\mathrm{T} \text { wave inversion } \\
\mathrm{V}_{4}, 5,6\end{array}$ \\
\hline 5 & Sinus & - & - & + & - & $+180^{\circ}$ & Clockwise & \\
\hline
\end{tabular}

LAH = left atrial hypertrophy; $L V H=$ left ventricular hypertrophy; $R A H=$ right atrial hypertrophy; $R V H=$ right ventricular hypertrophy.

TABLE 2 Chest $x$-ray findings: values graded out of 4

\begin{tabular}{|c|c|c|c|c|c|c|c|}
\hline Case & $\begin{array}{l}\text { Cardiothoracic } \\
\text { ratio }\end{array}$ & $\begin{array}{l}\text { Right atrial } \\
\text { enlargement }\end{array}$ & $\begin{array}{l}\text { Left atrial } \\
\text { enlargement }\end{array}$ & $\begin{array}{l}\text { Main pulm. } \\
\text { artery } \\
\text { enlargement }\end{array}$ & $\begin{array}{l}\text { Periph. pulm. } \\
\text { vasculature }\end{array}$ & $\begin{array}{l}\text { Upper lobe } \\
\text { pulm. vein } \\
\text { enlargement }\end{array}$ & Aortic arch \\
\hline I & 0.55 & +2 & o & +2 & Normal & $+I$ & Left \\
\hline 2 & 0.57 & +2 & o & $+\mathrm{I}$ & +3 & +2 & Left \\
\hline 3 & 0.58 & $+\mathrm{I}$ & +3 & +2 & Normal & $+I$ & Left \\
\hline 4 & 0.61 & 0 & 0 & 0 & $+I$ & 0 & Left \\
\hline 5 & 0.67 & $+I$ & $\circ$ & 0 & +2 & 0 & Left \\
\hline
\end{tabular}

TABLE 3 Haemodynamic data

\begin{tabular}{|c|c|c|c|c|c|c|c|c|}
\hline \multicolumn{9}{|c|}{ Pressure $(\mathrm{mmHg})$} \\
\hline Case No. & $\begin{array}{l}\text { Right } \\
\text { atrium }\end{array}$ & $\begin{array}{l}\text { Right } \\
\text { ventricle }\end{array}$ & $\begin{array}{l}\text { Pulmonary } \\
\text { artery }\end{array}$ & $\begin{array}{l}P A \\
\text { wedge }\end{array}$ & $\begin{array}{l}\text { Left } \\
\text { atrium }\end{array}$ & $\begin{array}{l}\text { Left } \\
\text { ventricle } \\
\text { (body) }\end{array}$ & $\begin{array}{l}\text { Left } \\
\text { ventricle } \\
\text { (outflow) }\end{array}$ & $\begin{array}{l}\text { Ascending } \\
\text { aorta }\end{array}$ \\
\hline $\begin{array}{l}\text { I } \\
2 \\
3 \text { (preop) } \\
3 \text { (postop) } \\
4 \\
5\end{array}$ & $\begin{array}{l}1 /-3 \\
6 /-2 \\
5 / 0 \\
5 / 2 \\
14 / 2 \\
1 /-6\end{array}$ & $\begin{array}{l}70 / 0 \\
86 /-1 \\
30 / 0 \\
45 / 3 \\
40 / 0 \\
34 / 0\end{array}$ & $\begin{array}{l}55 / 40 \\
80 / 63 \\
30 / 8 \\
42 / 30 \\
40 / 20 \\
30 / 10\end{array}$ & $\begin{array}{l}30 / 22 \\
30 / 20 \\
- \\
31 / 18 \\
25 / 8 \\
-\end{array}$ & $\begin{array}{l}- \\
\overline{12 / 5} \\
- \\
6 /-6\end{array}$ & $\begin{array}{l}70 / 2 \\
100 / 0 \\
196 / 10 \star \\
160 / 2 \\
240 / 8 \\
102 / 29 t\end{array}$ & $\begin{array}{l}70 / 2 \\
100 / 0 \\
- \\
140 / 4 \\
135 / 8 \\
102 / 29 \dagger\end{array}$ & $\begin{array}{l}70 / 40 \\
83 / 61 \\
- \\
140 / 83 \\
120 / 55 \\
126 / 59\end{array}$ \\
\hline
\end{tabular}

* Post-extrasystolic pressures; † not simultaneous with LA.

$\mathbf{Q p}=$ pulmonary blood flow, $\mathbf{Q}=$ Systemic blood flow, $\mathbf{R p}=$ total pulmonary resistance,

$\mathbf{R p a}=$ pulmonary vascular resistance, $\mathrm{Rs}=$ total systemic resistance. 
These are principally determined by which haemodynamic abnormalities dominated the clinical picture. Table 4 lists the abnormalities present in each patient in rough order of importance and summarizes surgical treatment. Oxygen saturations revealed a right-to-left shunt in only one patient (Case 2). This was at ventricular level, and the systemic arterial oxygen saturation was 69 per cent. Left-to-right shunts at ventricular level were demonstrated in Cases I, 2, and 4. The history, results of physical examination, angiocardiography, and operation or necropsy are presented individually.

\section{Case I}

\section{Case reports}

This girl had been dyspnoeic upon exertion from birth, but not orthopnoeic, and her exercise tolerance was considerably reduced when she was first seen by us at 2 years of age.

The physical signs were of isolated severe mitral stenosis, and included a left parasternal lift, a palpable second heart sound, a pulmonary ejection click, and a long apical mid-diastolic rumble with presystolic accentuation. The second heart sound was closely split, with a loud pulmonary component. There was no systolic murmur, no mitral opening snap, and no abnormality of the pulses.

Selective retrograde left ventricular angiocardiography indicated a large high ventricular septal defect, through which the right ventricle and pulmonary artery opacified. Pulmonary venous return was normal to an enlarged left atrium. Between the left atrium and left ventricle was a constant, thin, crescentic filling defect which did not move as mitral leaflets do (Fig. I). The mitral orifice appeared somewhat reduced in diameter. Two papillary muscles were identified in the left ventricle and the appearance of parachute mitral valve (v.i.) was not present. No coarctation or subaortic stenosis was seen.

Open intracardiac operation (P.B.D.), using the deep hypothermic circulatory arrest technique, was performed when she was 2 years old and weighed $8 \mathrm{~kg}$. A subcristal ventricular septal defect was exposed through the right atrium and closed with a patch. The atrial septum was then opened and a supravalvar mitral ring found with a $4 \mathrm{~mm}$ orifice. The shelf of thin tissue surrounded the mitral orifice and was closely related to and fused with the base of the mitral leaflets. The shelf was

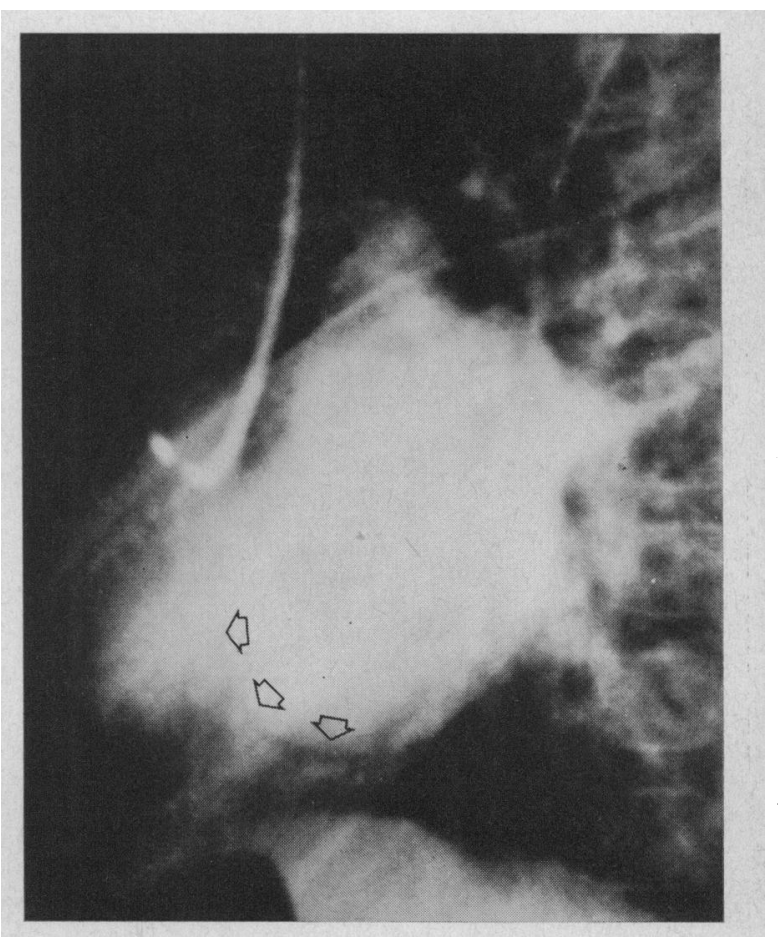

FIG. I Case I. Lateral view of pulmonary venous phase of selective left ventricular angiocardiogram. Contrast medium entered the pulmonary circulation via a ventricular septal defect. The left atrium is greatly enlarged and arrows demonstrate the thin crescentic filling defect presumed due to a supravalvar mitral ring.

\begin{tabular}{|c|c|c|c|c|c|c|c|c|}
\hline \multirow[t]{2}{*}{$\begin{array}{l}\text { Femoral } \\
\text { artery }\end{array}$} & \multirow[t]{2}{*}{$\begin{array}{l}\text { Response to } \\
\text { post-extra- } \\
\text { systolic beat }\end{array}$} & \multicolumn{3}{|c|}{$\begin{array}{l}\text { Blood flows } \\
\left(l . / \min \text { per } m^{2}\right)\end{array}$} & \multicolumn{3}{|c|}{$\begin{array}{l}\text { Vascular } \\
\text { resistances } \\
\text { (units } m^{2} \text { ) }\end{array}$} & \multirow[b]{2}{*}{$R p / R s$} \\
\hline & & $Q p$ & $Q s$ & $Q p / Q s$ & $R_{p}$ & $R s$ & $R p a$ & \\
\hline $\begin{array}{l}65 / 40 \\
71 / 60 \\
92 / 46^{\star} \\
155 / 70 \\
80 / 52 \\
-\end{array}$ & $\begin{array}{l}\text { Normal } \\
\text { Normal } \\
\text { Abnormal } \\
\text { Normal } \\
\text { Normal } \\
\text { Normal }\end{array}$ & $\begin{array}{l}3 \cdot 7 \\
5 \cdot 4 \\
2 \cdot 6 \\
2 \cdot 7 \\
4 \cdot 3 \\
1 \cdot 8\end{array}$ & $\begin{array}{l}2 \cdot 5 \\
3 \cdot 1 \\
2 \cdot 6 \\
2 \cdot 7 \\
3 \cdot 6 \\
1 \cdot 8\end{array}$ & $\begin{array}{l}I \cdot 5 \\
I \cdot 8 \\
I \\
I \\
I \cdot 2 \\
I\end{array}$ & $\begin{array}{l}12 \\
15 \\
5 \cdot 7 \\
11 \cdot 7 \\
6 \cdot 3 \\
13 \cdot 6\end{array}$ & $\begin{array}{l}20 \\
26 \\
23 \cdot 3 \\
31 \cdot 5 \\
20 \cdot 7 \\
35 \cdot 7\end{array}$ & $\begin{array}{l}5 \cdot 6 \\
9 \cdot 9 \\
2 \cdot 7 \\
1 \cdot 5 \\
1 \cdot 9 \\
-\end{array}$ & $\begin{array}{l}0.6 \\
0.6 \\
0.25 \\
0.4 \\
0.3 \\
0.4\end{array}$ \\
\hline
\end{tabular}


TABLE 4 Summary of anomalies

\begin{tabular}{|c|c|c|c|}
\hline $\begin{array}{l}\text { Case } \\
\text { No. }\end{array}$ & $\begin{array}{l}\text { Age at } \\
\text { operation } \\
(y r)\end{array}$ & Anomalies & Surgical procedure \\
\hline I & 2 & $\begin{array}{l}\text { Subcristal ventricular septal defect; supravalvar } \\
\text { mitral ring }\end{array}$ & $\begin{array}{l}\text { Transatrial patch repair of ventricular } \\
\text { septal defect; } \\
\text { excision supravalvar ring }\end{array}$ \\
\hline 2 & 13 & $\begin{array}{l}\text { Double outlet right ventricle with } \\
\text { d-malposition of the great arteries; } \\
\text { parachute mitral valve; } \\
\text { supravalvar mitral ring; } \\
\text { mild subaortic muscular obstruction; } \\
\text { anomalous tricuspid valve; } \\
\text { pseudocoarctation of the aorta }\end{array}$ & $\begin{array}{l}\text { Intraventricular correction of double } \\
\text { outlet right ventricle; } \\
\text { excision supravalvar ring; } \\
\text { mitral valve replacement; } \\
\text { resection of subaortic obstruction }\end{array}$ \\
\hline 3 & IO & $\begin{array}{l}\text { Parachute mitral valve; } \\
\text { subaortic stenosis }\end{array}$ & $\begin{array}{l}\text { Mitral valve replacement; } \\
\text { excision subaortic stenosis }\end{array}$ \\
\hline 4 & 6 & $\begin{array}{l}\text { Discrete subaortic stenosis; } \\
\text { aortic valve stenosis (bicuspid); } \\
\text { ventricular septal defect; } \\
\text { parachute mitral valve; } \\
\text { pseudocoarctation of aorta }\end{array}$ & $\begin{array}{l}\text { Aortic valvotomy; } \\
\text { excision subaortic stenosis }\end{array}$ \\
\hline 5 & - & $\begin{array}{l}\text { Preductal coarctation of aorta; } \\
\text { parachute mitral valve; } \\
\text { bicuspid aortic valve }\end{array}$ & - \\
\hline
\end{tabular}

excised as much as possible. The underlying mitral tissue looked normal though no clear view of the papillary muscle anatomy could be seen.

After correction the pressures were: left ventricle I $10 / 10 \mathrm{mmHg}$, right ventricle $50 / \mathrm{IO} \mathrm{mmHg}$, left atrium (mean) $14 \mathrm{mmHg}$, right atrium (mean) $12 \mathrm{mmHg}$.

The child has done well, with increased growth and greatly increased effort tolerance. There is still a short apical mid-diastolic murmur and palpable right ventricle.

\section{Case 2}

This girl had a history of recurrent chest infections and feeding difficulties in infancy. Cyanosis was first noted at 9 months of age. She had been diagnosed as having Eisenmenger's complex after cardiac catheterization at the age of 8 years. A prominent apical mid-diastolic murmur was noted at that time, but its origin could not be explained. She became progressively more cyanotic, and dyspnoeic on the slightest exertion, but never

FIG. 2 a) Case 2. Diagrammatic representation of Fig. 2 b), to demonstrate the components of a parachute mitral valve. The chordae tendineae are drawn for clarification, but are not demonstrated angiocardiographically. The position of the ascending aorta and aortic valve are in part derived from other frames of the same angiocardiogram, as is the site of the ventricular septal defect. b) Case 2. Lateral view of selective left ventricular angiocardiogram during diastole. The injection was made through the lower catheter, which has traversed a ventricular septal defect from the right ventricle. A second catheter has been advanced into the pulmonary artery via the superior vena cava and right heart. The 'egg-timer' appearance of parachute mitral valve is seen as a filling defect in the left ventricle. The ventricular septal defect lies well below both semilunar valves and most of the contrast medium injected has entered the pulmonary artery. There is mitral-aortic discontinuity. c) Case 3. Selective left ventricular angiocardiogram. Lateral view of diastolic film. The enlarged single papillary muscle (PM) together with non-opacified blood trapped within the cone-shaped mitral leaflets (MV) make up the 'egg-timer' filling defect. There is moderate regurgitation of contrast medium into the enlarged left atrium. $d$ ) Case 5. Diastolic film: lateral projection of selective left ventricular angiocardiogram. The 'egg-timer' deformity of the mitral valve apparatus is demonstrated with black arrows.

$A O=$ ascending aorta, $L C=$ left circumflex coronary artery, $L V=$ left ventricle, $M V=$ mitral valve, $P A=$ pulmonary artery, $P M=$ papillary muscle, $R V=$ right ventricle, $V=$ ventricular septal defect. 

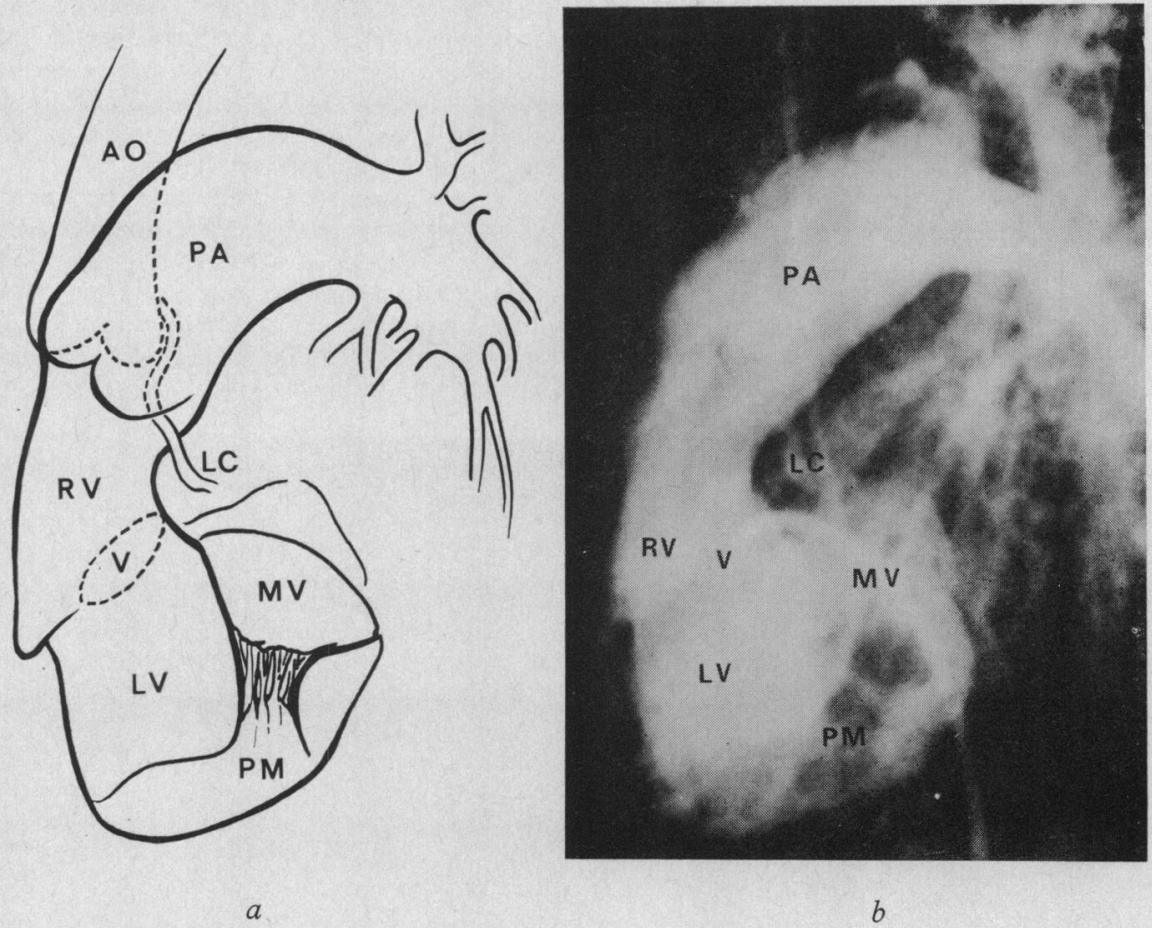

$b$
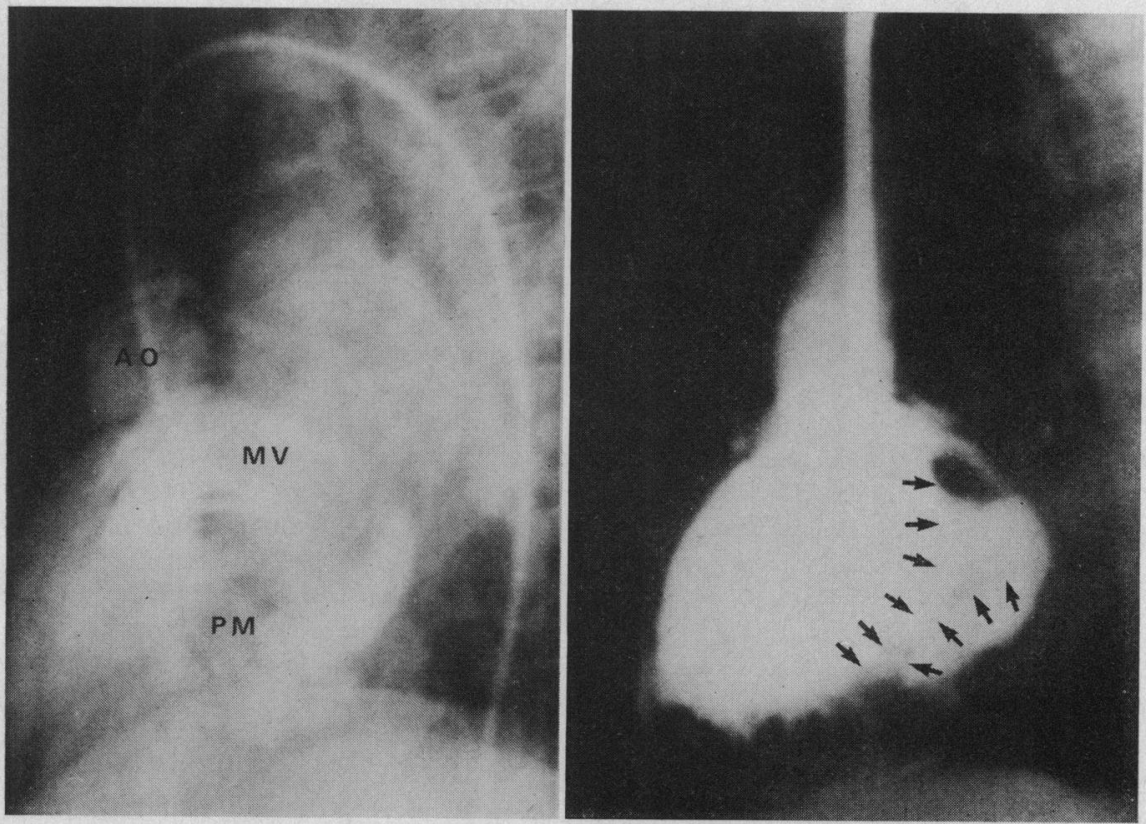

c 
orthopnoeic, and had had several episodes of angina-like pain.

On physical examination at the age of 13 years she was severely cyanosed, with pronounced digital clubbing. The peripheral pulses were normal, but her jugular venous pressure was $I \mathrm{~cm}$ above the sternal angle at $45^{\circ}$, with the ' $a$ ' and ' $v$ ' waves of equal height. There was severe right ventricular hypertrophy on palpation, with both heart sounds palpable. The first and second heart sounds were single. At the lower left sternal border there was a long, early systolic murmur of moderate intensity. There was also a very loud apical mid-diastolic murmur with presystolic accentuation but no snap.
Selective anterograde right and left ventricular, and retrograde aortic root angiograms were performed. With the catheter through a ventricular septal defect, a normally situated left ventricle was seen, from which the only exit was a large ventricular septal defect which was well below both semilunar valves (Fig. 2b). The mitral valve was displaced somewhat downward from its normal position, and the leading edge of the anterior leaflet as seen in the frontal projection was unusually curved. In the lateral projection during diastole the 'eggtimer' appearance of parachute mitral valve was clearly seen (Fig. 2b). There was a well-developed bilateral conus and the aortic valve lay somewhat above and

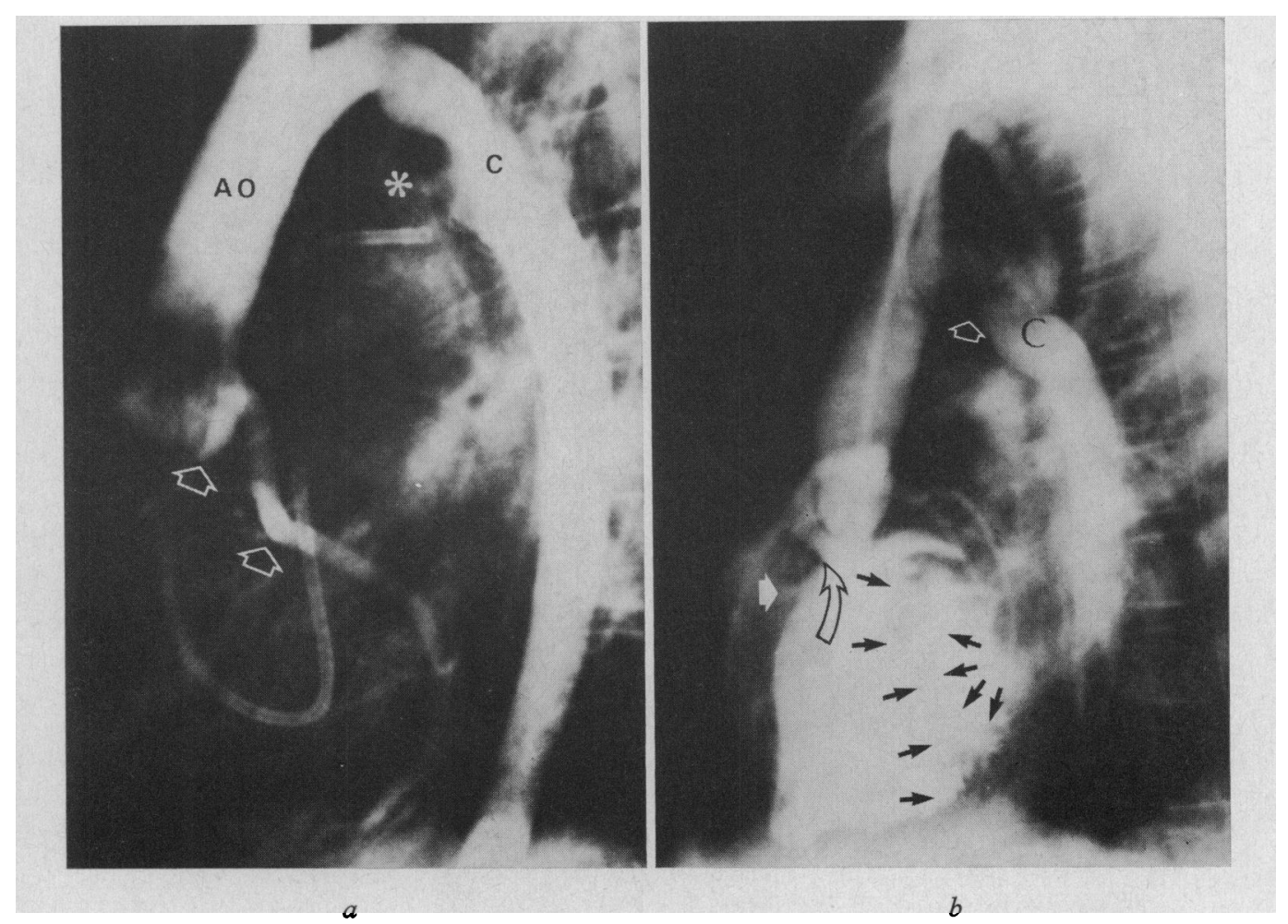

FIG. 3 a) Case 2. Lateral projection, retrograde aortogram. A second transvenous catheter lies in the pulmonary artery. There is a pseudocoarctation $(C)$ associated with pronounced distortion of the aortic isthmus, and an aortic ductus diverticulum $\left(^{\star}\right)$. The presence of aortic/ mitral discontinuity is demonstrated by the two white arrows, one pointing to the aortic annulus, and the other to the kink in the greatly enlarged circumflex left coronary artery, at the point where it passes into the atrioventricular groove. This is an external landmark of the mitral annulus. This interpretation of the appearances resulted from multiple comparisons of the position of the circumflex artery and mitral valve annulus in pairs of frames from the left ventricular and aortic root injections, matched for timing within the cardiac cycle. b) Case 4. Diastolic frame, selective retrograde left ventricular angiocardiogram in lateral projection. An elongated, faint, filling defect (solid black arrows) connects the mitral orifice with the single posteromedial papillary muscle, thus giving rise to an 'egg-timer' deformity. Above this (hollow black arrow) is a subaortic stenosis. Note the similarity of appearance of the pseudocoarctation in this Figure and in Fig. 3a. A hollow white arrow marks the aortic ductus diverticulum. $A$ solid white arrow marks the very small ventricular septal defect, and an open white arrow points to a ductus diverticulum. $A O=$ aorta, $C=$ coarctation. 
anterior to, and well to the right of the pulmonary valve. There was a mild preductal coarctation associated with considerable aortic distortion and a short aortic ductus diverticulum (Fig. 3a).

Open intracardiac operation was performed (P.B.D.) under cardiopulmonary bypass and moderate total body hypothermia $\left(30^{\circ} \mathrm{C}\right)$.

The findings were: double outlet right ventricle with the aorta lying anteriorly and to the right; the ventricular septal defect was large and some $5 \mathrm{~cm}$ from either semilunar valve; the anterior cusp of the tricuspid valve was attached around the superior margins of the ventricular septal defect; there was pronounced subaortic muscular obstruction, and a supravalvar mitral stenosing ring and underlying this a parachute mitral valve. The subaortic muscle was resected and after detaching the abnormal tricuspid insertion an intraventricular connexion between the left ventricle and the aorta was created. The tricuspid tissue was reattached to the right side of the patch. The mitral valve was exposed by a transseptal right atrial incision. The supravalvar ring was excised and the deformed mitral valve was removed and replaced by a $19 \mathrm{~mm}$ Bjork-Shiley prosthesis.

After correction pressures were: left ventricle $115 / 15$, aorta $85 / 44$, right ventricle $70 / 8$, left atrium (mean) 20 , right atrium (mean) 10 $\mathrm{mmHg}$.

Postoperatively the child needed intensive management for several days but then recovered well. She was discharged from hospital on the Igth postoperative day.

Since operation she has made steady progress, with good effort tolerance, no chest pain, and resumption of normal schooling.

\section{Case 3}

A heart murmur was first noted in this boy at age 5 years. Over the next 5 years he grew slowly and developed exertional dyspnoea and tiredness and had a possible syncopal episode at age ro years. There was a family history of two maternal relatives dying suddenly during exertion at age 18 and 21 years, respectively. At 6 years of age, left ventricular and femoral artery puncture had demonstrated no systolic gradient except during postextrasystolic beats.

On physical examination at ro years old, his pulses were synchronous, regular, and jerky. The left ventricular impulse was forceful. A systolic thrill was palpable at the apex beat and suprasternal notch and there was a palpable carotid thrill. A long ejection systolic murmur was heard maximally at the lower left sternal border with a third heart sound and mid-diastolic murmur at the the apex.

Selective retrograde and antegrade right ventricular angiocardiograms indicated that the right ventricle and pulmonary arteries were normal. Pulmonary venous return was to an enlarged left atrium. There was no crescentic shadow between the left atrium and ventricle, but the mitral valve showed the 'egg-timer' deformity of parachute mitral valve (Fig. 2c). Though the single papillary muscle did arise from the posterior left ventricular wall, it was much thicker during systole than in the other patients (Fig. 4a), when it divided the left ventricle into two compartments with only a narrow, superior communication between them. In the frontal view there was a discrete subaortic diaphragm in the classical position. There was moderately severe mitral regurgitation, but no coarctation or ventricular septal defect.

At open intracardiac operation in August 1969 (M.I.I.), before starting heart-lung bypass the left ventricular/ aortic peak systolic pressure gradient was found to be $80 \mathrm{mmHg}$, but was abolished by injection of intravenous phenylephrine. Digital exploration of the left atrium revealed an important jet of mitral regurgitation. The aortic valve was slightly thickened but otherwise normal. There was a stenotic diaphragm, barely admitting the tip of a little finger, $15 \mathrm{~mm}$ below the aortic annulus, and a parachute mitral valve, whose grossly hypertrophied papillary muscle divided the left ventricular cavity into two compartments. The two mitral cusps each had two very thick portions, giving the impression of a quadricuspid valve.

The diaphragm and mitral valve were excised, and the latter replaced with a frame mounted autologous fascia lata valve $22 \mathrm{~mm}$ in diameter. At the end of the procedure there was no aortic valve gradient.

The postoperative period was relatively uneventful. Thereafter the child did well, apart from developing recurrent episodes of nocturnal cough. Reinvestigation three years after operation with angiocardiography (Fig. 4b, Table 3) indicated a moderate gradient across the fascial valve which was competent. There was trivial residual subaortic stenosis, and the response to postextrasystolic beats of the left ventricular and aortic pressure was normal. There were no angiocardiographic features of hypertrophic obstructive cardiomyopathy.

\section{Case 4}

This girl was asymptomatic apart from slow weight gain in infancy.

On physical examination at 6 years of age, she was acyanotic, with normal peripheral pulses. There was a systolic thrill extending from the apex to both carotid arteries, and a diastolic apical thrill. The apical impulse was single and thrusting. There was a long, rough systolic murmur over most of the praecordium and a loud apical mid-diastolic murmur, of moderate length and without presystolic accentuation. The second heart sound was normal and there was no click or snap.

Angiocardiography was carried out with selective injection into the pulmonary artery and left ventricle. There was mild enlargement of the left atrium but no evidence of any supravalvar diaphragm. The mitral valve showed the 'egg-timer' deformity and there was a discrete subaortic diaphragm, and a small ventricular septal defect. The aortic valve cusps were thickened and there was a mild aortic coarctation with considerable tortuosity at the isthmus (Fig. 3b).

In view of the severity of the subaortic obstruction, open intracardiac operation was performed in November 1970 (P.B.D.). A fibrous subaortic diaphragm was excised and one fused commissure of a basically bicuspid aortic valve incised. The site of the ventricular 


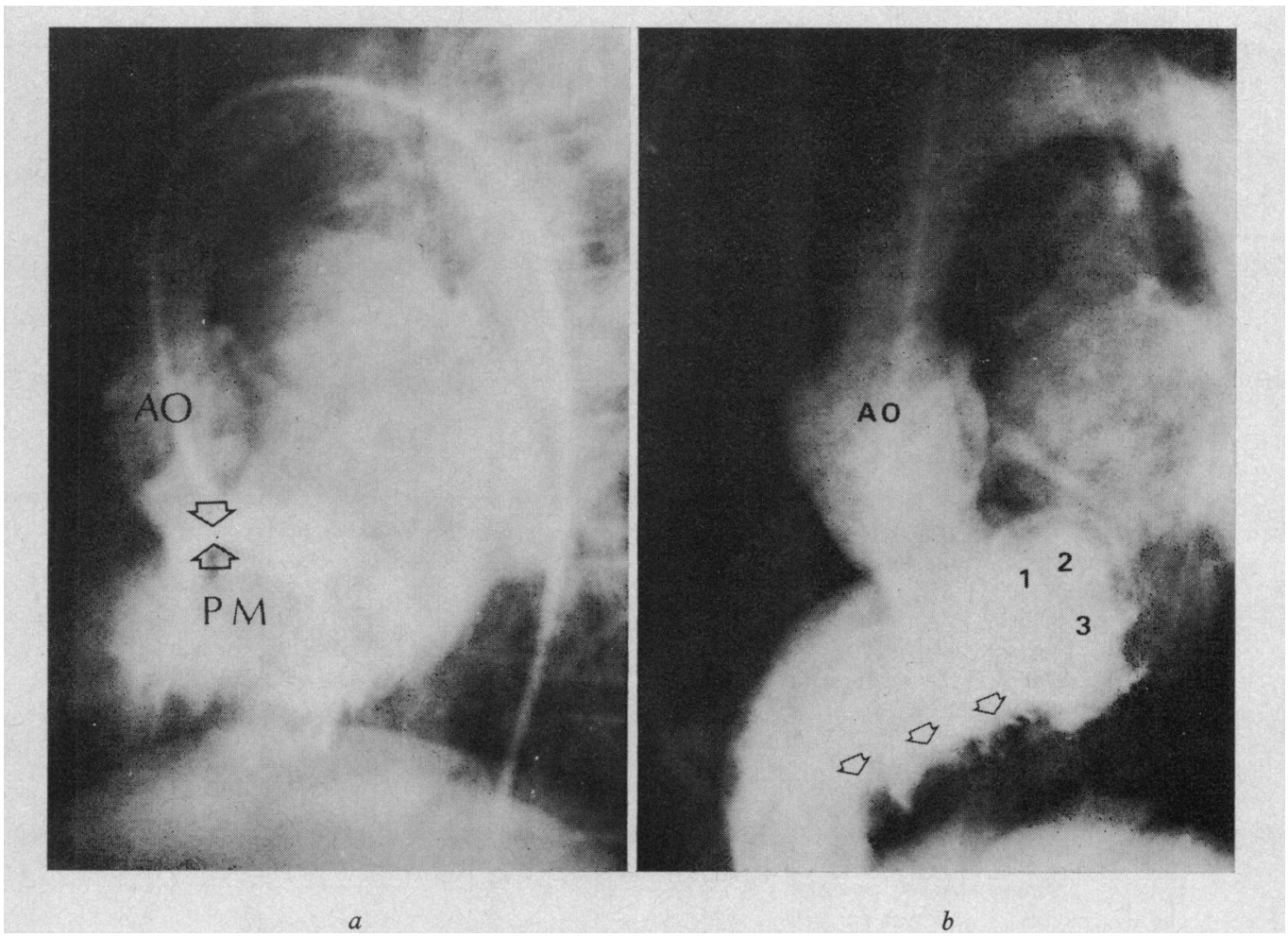

FIG. 4 a) Case 3. Preoperative retrograde left ventricular angiocardiogram, lateral view, during systole. The grossly hypertrophied papillary muscle (PM) divides the left ventricular cavity into two compartments, separated by a narrow channel (between arrows) superior to the papillary muscle. The catheter tip lies posterior to this channel, where the left ventricular pressure was raised. There is moderate mitral regurgitation. $b$ ) Case 3. Postoperative angiocardiogram under the same conditions as Fig. 4a. After resection of the parachute mitral valve, there is no intraventricular obstruction. Arrows mark the stump of the papillary muscle. $1,2,3$ are the three cusps of the fascia lata mitral valve replacement. $A O=$ aorta, $P M=$ papillary muscle.

septal defect was not apparent through the aortic root and in view of its small size was not explored further. Pressure measurements suggested that the mitral obstruction was not severe, and in view of the likely consequences of attempted relief of stenosis at this age, the mitral valve was not explored.

Two years after operation the child is symptomless. Left ventricular hypertrophy is reduced clinically and electrocardiographically. The physical signs of a small ventricular septal defect and moderate mitral stenosis remain.

\section{Case 5}

This baby, weighing $2097 \mathrm{~g}$, was product of a 38-week breech delivery and was admitted as an emergency at I month of age with a history of dyspnoea and feeding difficulties for a week.

On physical examination she was acyanotic with a respiratory rate of $120 / \mathrm{min}$, but no hepatomegaly. The upper limb pulses were bounding but the femoral pulses were weak. The flush pressures in the arms were
$120 \mathrm{mmHg}$ and in the legs $60 \mathrm{mmHg}$. Palpation of the praecordium was normal. On auscultation the first and second heart sounds were normal apart from accentuation of pulmonary closure. There was a short unimpressive systolic and a loud mid-diastolic murmur at the apex.

Angiocardiography with selective retrograde injection demonstrated a hypertrophied left ventricle. The mitral valve was competent, but in diastole the characteristic 'egg-timer' appearance of parachute mitral valve was seen (Fig. 2d). Furthermore, the anterior leaflet was tethered inferiorly so that it could not move normally into the left ventricular outflow tract in diastole. In systole (Fig. 5) the single posteromedial papillary muscle thickened considerably. The aorta was hypoplastic distal to the right innominate artery and there was a severe coarctation in the classical site.

When the catheter was withdrawn from the left ventricle it was noted that the aortic diastolic pressure had fallen to $10 \mathrm{mmHg}$ and a hand injection of contrast medium into the aortic root showed severe aortic re- 


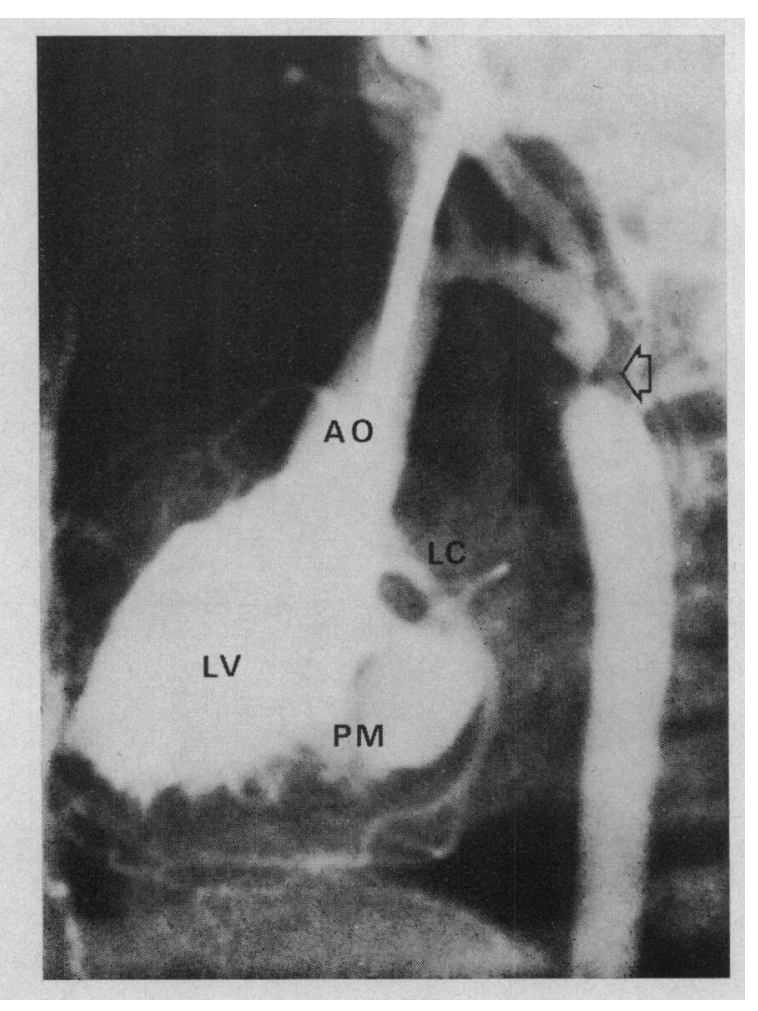

FIG. 5 Case 5. Systolic frame, lateral projection, of retrograde left ventricular angiocardiogram. An arrow marks a severe coarctation. Note the bulbous appearance of the single papillary muscle (PM). $A O=$ aorta,$L C=$ left circumflex coronary artery, $L V=$ left ventricle.

gurgitation. Some 8 hours later the child suffered a sudden cardiac arrest and died.

This was the only patient in whom a definite diagnosis of parachute mitral valve was made before operation or death.

Necropsy demonstrated a modified parachute valve (Shone et al., 1963; Davachi, Moller, and Edwards, 1971). There were actually two papillary muscles of very unequal size, both arising from the usual site of the posteromedial papillary muscle, with their origins about I $\mathrm{mm}$ apart. The posterior mitral leaflet was almost absent. The left ventricle was hypertrophied with whitish discoloration of the inner third of the myocardium, but not endocardium. Histology of this abnormal myocardium showed disrupted myocardial fibres, many of which were irregular in shape and contained cytoplasmic vacuoles. There was no supravalvar mitral ring. The aortic valve was bicuspid and there was a $3 \mathrm{~mm}$ perforation in one cusp. The aortic arch was hypoplastic and there was a severe preductal coarctation. The ductus arteriosus was barely patent and there was a patent foramen ovale.

\section{Discussion}

Parachute mitral valve and supravalvar mitral ring are at first sight different entities. They are discussed together because they both cause congenital mitral valve obstruction and frequently coexist with one another and with a complex of other abnormalities (suboartic stenosis, coarctation of the aorta, and to a lesser extent ventricular septal defect and bicuspid aortic valve) (Shone et al., 1963). Three of the patients described above had parachute mitral valve, one had supravalvar mitral ring, and one had both. Operative or postmortem confirmation of the diagnosis was obtained in all patients except Case 4. This patient, however, not only had angiographic appearances typical of parachute mitral valve (v.i.) together with haemodynamic evidence of mitral obstruction, but also all four of the above associated lesions.

An apical mid-diastolic murmur is common in patients with ventricular septal defect, coarctation of the aorta, and subaortic stenosis, without there being organic mitral stenosis. Thus the clinical recognition of mitral valve obstruction in the presence of these other lesions may not be easy.

One of the patients (Case 3) had obvious signs of mitral incompetence. In the remainder, whose mitral valves were competent, the apical middiastolic murmur was unduly prominent in the clinical picture as a whole. Obtaining a valid left atrial pressure therefore became a first priority in investigation. In both patients with large ventricular septal defects (Cases I and 2), the high values of total pulmonary resistance $(\mathbf{R p})$ and its ratio to systemic resistance (Rs) would have contraindicated surgery had not mitral obstruction been recognized. Values of pulmonary vascular resistance, though raised, were low enough to permit surgical correction of the important abnormalities with a moderate fall in right ventricular pressure as measured on the operating table after intracardiac correction. This was achieved without mitral valve replacement in the 2-year-old patient with supravalvar mitral ring, as has previously been reported in one ro-year-old patient (Lynch et al., 1962). Since the obstruction due to parachute mitral valve cannot be adequately corrected without mitral valve replacement (Terzaki et al., 1968), which may have disadvantages in small children (Robinson and Young, 1966), the preoperative distinction between these two causes of mitral obstruction is of considerable practical importance.

Carey, Sellers, and Shone (1964) stated that, 'it is unlikely, at present, that the definite diagnosis of a parachute mitral valve can be made by radiologic means'. 
Since then others (Terzaki et al., 1968; Simon, Friedman, and Roberts, 1969) have attempted to define angiocardiographic appearances specific for parachute mitral valve. These have included the demonstration of a single hypertrophied papillary muscle, a cone-shaped appearance of the mitral valve leaflets, and an abnormal systolic position of the mitral valve resulting in functional left ventricular outflow tract obstruction. If two papillary muscles could be confidently identified angiographically when they were in fact present, identification of a single papillary muscle would be a useful criterion for the diagnosis of parachute mitral valve. However, in a review (F. J. Macartney, 1973, unpublished data) of 50 consecutive, high quality left ventricular angiocardiograms performed in patients with congenital cardiac anomalies other than coarctation, subaortic stenosis, and left ventricular hypoplasia, and with no clinical, angiocardiographic, or haemodynamic evidence of mitral valve abnormalities, in Io per cent no papillary muscles were identified, and in 36 per cent only one papillary muscle was seen. Two papillary muscles were identified in 54 per cent. In this series it was noted that two papillary muscles were visualized in all II patients with valvular aortic stenosis, since this resulted in papillary muscle hypertrophy. The incidence of identification of both papillary muscles in patients without left ventricular outflow obstruction was only $4 \mathrm{I}$ per cent.

An abnormal systolic position of the mitral valve in apposition to the interventricular septum was not recognized in any of our patients with parachute mitral valve. One patient (Case 3) did nevertheless have severe functional subaortic stenosis as evidenced by the response to postextrasystolic beats and phenylephrine. Since phenylephrine abolished the left ventricular/aortic systolic pressure gradient, the obstruction produced by his discrete subaortic diaphragm cannot have been significant. Resection of the parachute mitral valve resulted in disappearance of functional subaortic stenosis. Review of his preand postoperative left ventricular angiocardiograms (Fig. 4) and operative findings suggest that it was the papillary muscle and not the mitral leaflets that caused functional subaortic stenosis, by dividing the left ventricular cavity into two portions during systole. This obstruction would be abolished by interventions such as phenylephrine, which increase left ventricular volume, thus allowing more room for the hypertrophied papillary muscle. Furthermore, the posterior site of origin of the single papillary muscle which was present in all 4 patients would be expected to prevent rather than cause apposition of the anterior leaflets of the mitral valve to the septum during systole.
The normal mitral valve has two leaflets in an anterior and posterior position. The papillary muscles are anterolateral and posteromedial, and chordae tendineae from each papillary muscle insert into both mitral cusps. Thus when the mitral valve opens there is a wide central orifice. If only a single papillary muscle is present and the chordae are somewhat short, the anterior and posterior leaflets are held together during diastole, so that blood must egress through the interchordal spaces (Shone et al., 1963).

If the single papillary muscle lies in the normal position of the posteromedial papillary muscle, as was demonstrated in these 4 patients, the normal diastolic anterior movement of the anterior leaflet will be restricted and there may be loss of the usual appearance of swinging of the anterior leaflet on the left and non-coronary aortic sinuses, whereby mitral-aortic continuity is normally diagnosed (Hallerman et al., 1970). This was evident in Case 5 and present to a lesser extent in Case 4. In Case 2 restricted movement of the anterior mitral leaflet was obvious, but mitral/aortic continuity was in any case not present as both great arteries originated from the right ventricle.

Angiocardiographic diagnosis of parachute mitral valve is not made easier by the fact that its two major components, the valve leaflets and papillary muscle, are best visualized at different times in the cardiac cycle. The leaflets are best observed during ventricular diastole when unopacified blood is traversing the mitral orifice, whereas papillary muscles are easier to identify during systole when they are shorter and thicker. Nevertheless we believe that parachute mitral valve can be identified with confidence by the subtle but unmistakable appearance of an 'egg-timer' shaped filling defect during ventricular diastole observed on the lateral angiocardiogram. The posterosuperior portion of the egg-timer is formed by the coned mitral leaflets and chordae tendineae, and the anteroinferior portion by the single papillary muscle (Fig. 2a). In systole the papillary muscle alone is visualized, but this is not a specific finding, for reasons already stated. Since the papillary muscle has to be visualized in diastole, it is clear that it will only be seen on the highest quality angiocardiograms.

The other abnormalities of mitral valve structure noted in some, but not all, of these patients, were irregularity of the margin of the anterior mitral leaflet, together with a more than usually curved free edge, probably due to the restricting influence of the tethering chordae tendineae.

For the reasons already stated parachute mitral valve must, by its very nature, result in some mitral valve obstruction. In the one patient in whom the 
valve was predominantly incompetent, there was also pronounced cusp thickening and deformity. Though mitral incompetence has been described in previous reports (Terzaki et al., 1968; Glancy et al., 197I), the majority have had pure stenosis of the valve.

The association of parachute mitral valve with origin of both great vessels from the right ventricle has been previously noted in 3 patients (Davachi et al., 197 I). To our knowledge, Case 2 in this series is the first to have undergone successful surgical correction, and is of further particular interest since, though the ventricular septal defect was some $5 \mathrm{~cm}$ below the pulmonary valve, left ventricular blood was preferentially directed into the pulmonary artery rather than the aorta. This observation conflicts with the classic view of the haemodynamics of origin of both great vessels from the right ventricle, which is that when the ventricular septal defect is subcristal, the crista deflects left ventricular blood preferentially into the aorta (Neufeld et al., 1962). The unusual streaming of blood in this patient may have been due to the abnormal attachment of tricuspid valvar tissue to the superior rim of the ventricular septal defect.

Preoperative diagnosis of supravalvar mitral ring has only been reported in one patient (Lynch et al., 1962) and never angiocardiographically. Though it was specifically searched for preoperatively in both patients with this abnormality, it was diagnosed in neither. Transient regurgitation into the left atrium not infrequently demonstrates well a left atrial membrane in cor triatriatum (Miller et al., 1964), but regurgitation did not occur in these patients. Retrospectively it was possible to identify a thin crescentic defect between the left atrium and left ventricle (Fig. I) during pulmonary venous return in both Case $I$ and 2. This appearance has not been observed by us nor reported by others in congenital mitral valve stenosis, so it was presumably due to the supraventricular diaphragm. However the mitral leaflets could not be identified as separate from this structure. A supravalvar ring is so close to the mitral valve leaflets, and mitral leaflet abnormalities coexist so commonly with supravalvar ring, that exact preoperative distinction between congenital supravalvar and valvar mitral stenosis is inevitably difficult. Our current policy in patients such as Case 4 would be to explore the left atrium even if mitral obstruction is mild and no supravalvar diaphragm has been visualized angiographically, in the hope of finding an easily resectable supravalvar ring. The postoperative course in the 4 patients operated on was relatively uneventful. This re-emphasizes the possibilities of complex intracardiac corrections for con- genital heart disease, provided that the significant haemodynamic lesions are recognized preoperatively and corrected at surgery.

\section{References}

Anabtawi, I. N., and Ellison, R. G. (1965). Congenital stenosing ring of the left atrioventricular canal (supravalvular mitral stenosis). Fournal of Thoracic and Cardiovascular Surgery, 49, 994.

Braunwald, E., Lambrew, C. T., Rockoff, S. D., Ross, J., Jr., and Morrow, A. G. (1964). Idiopathic hypertrophic subaortic stenosis: I. A description of the disease based upon an analysis of 64 patients. Circulation, 29-30, Suppl. 4, 3 .

Carey, L. S., Sellers, R. D., and Shone, J. D. (I964). Radiologic findings in the developmental complex of parachute mitral valve, supravalvular ring of left atrium, subaortic stenosis, and coarctation of aorta. Radiology, 82, 1 .

Cassano, G. B. (1964). Congenital annular stenosis of the left atrioventricular canal: so-called supravalvular mitral stenosis. American fournal of Cardiology, 13, 708.

Davachi, F., Moller, J. H., and Edwards, J. E. (I97I). Diseases of the mitral valve in infancy. An anatomic analysis of 55 cases. Circulation, 43, 565.

Glancy, D. L., Chang, M. Y., Dorney, E. R., and Roberts, W. C. (I97I). Parachute mitral valve: further observations and associated lesions. American fournal of Cardiology, 27, 309.

Hallerman, F. J., Kincaid, O. W., Ritter, D. G., and Titus, J. L. (1970). Mitral-semilunar valve relationships in the angiography of cardiac malformations. Radiology, 94, 63.

Johnson, N. J., and Dodd, K. (1957). Obstruction to left atrial outflow by a supravalvular stenosing ring. Fournal of Pediatrics, 5I, I90.

Kappagoda, C. T., and Linden, R. J. (1972). A critical assessment of an open circuit technique for measuring oxygen consumption. Cardiovascular Research, 6, 589.

LaFarge, C. G., and Miettinen, O.S. (I970). The estimation of oxygen consumption. Cardiovascular Research, 4, 23.

Lynch, M. F., Ryan, N. J., Williams, C. R., Cayler, G. G., Richardson, W. R., Campbell, G. S., and Taybi, H. (1962). Preoperative diagnosis and surgical correction of supravalvular mitral stenosis and ventricular septal defect. Circulation, 25, 854.

Manubens, R., Krovetz, L. J., and Adams, P., Jr. (1960). Supravalvular stenosing ring of the left atrium. American Heart Fournal, 60, 286.

Miller, G. A. H., Ongley, P. A., Anderson, M. W., Kincaid, O. W., and Swan, H. J. C. (I964). Cor triatriatum. Hemodynamic and angiocardiographic diagnosis. American Heart fournal, 68, 298.

Neufeld, H. N., Lucas, R. V., Jr., Lester, R. G., Adams, P., Jr., Anderson, R. C., and Edwards, J. E. (I962). Origin of both great vessels from the right ventricle without pulmonary stenosis. British Heart fournal, 24, 393.

Rao, S., Anderson, R. G., Lucas, R. V., Jr., Castenada, A., Ibarra-Perez, C., Korns, M. E., and Edwards, J. E. (I969). Clinical pathologic conference. American Heart fournal, $77,538$.

Robinson, G., and Young, D. (1966). Secondary implantation of a mitral valve prosthesis in a child. Annals of Thoracic Surgery, 2, 208.

Rogers, H. M., Waldron, B. R., Murphey, D. F. H., and Edwards, J. E. (1955). Supravalvular stenosing ring of left atrium in association with endocardial sclerosis (endocardial fibroelastosis) and mitral insufficiency. American Heart fournal, 50, 777. 
Shone, J. D., Sellers, R. D., Anderson, R. C., Adams, P., Jr., Lillehei, C. W., and Edwards, J. E. (1963). The developmental complex of 'parachute mitral valve', supravalvular ring of left atrium, subaortic stenosis, and coarctation of aorta. American fournal of Cardiology, 11, 714.

Simon, A. L., Friedman, W. F., and Roberts, W. C. (1969). The angiographic features of a case of parachute mitral valve. American Heart fournal, 77, 809.
Terzaki, A. K., Leachman, R. D., Ali, M. K., Hallman, G. L., and Cooley, D. A. (1968). Successful surgical treatment for 'parachute mitral valve' complex: report of 2 cases. Fournal of Thoracic and Cardiovascular Surgery, 56, I.

Requests for reprints to Dr. F. J. Macartney, Killingbeck Hospital, York Road, Leeds LSI4 6UQ. 